Journal of Awareness

Cilt / Volume 5, Say1 / Issue 2, 2020, pp. 159-168

E - ISSN: 2149-6544

URL: https://www.ratingacademy.com.tr/ojs/index.php/joa

DOİ: https://doi.org/10.26809/joa.5.013

Araştırma Makalesi / Research Article

\title{
EXAMINING THE IMPACT OF INDUSTRY 4.0 ON EDUCATION
}

\author{
Hanife AKGÜL* \& Zeynep AYER** \\ * Assist. Prof. Dr., Çanakkale Onsekiz Mart University, \\ TURKEY, e-mail: hanifeakgul38@gmail.com \\ ORCID: https://orcid.org/0000-0003-3574-394X \\ ** Research Assistant, Canakkale Onsekiz Mart University, Communication Faculty, \\ TURKEY, e-mail: ayerzeynep@gmail.com \\ ORCID: https://orcid.org/0000-0003-4107-0171
}

Received: 25 April 2020; Accepted: 5 May 2020

\begin{abstract}
Industry 4.0 is the concept that has been on the agenda for nearly a decade; but other than those closely involved in the issue, it is a little-known concept yet. Industry 4.0, which expresses the Fourth Industrial Revolution, promises to make production with smart factories and digital Technologies with almost no need for labor. Nowadays, when the technology develops quite fast, people's daily life styles change. In occupational groups where technology use is intense, there are differentiations in the way people express their feelings not only in business or academic life but also in private life.

In order to capture Industry 4.0, it is necessary to design, develop and produce technology in every field. However, in addition to production, it is important to train qualified labor force who can use this new technology. Taking into account that daily ordinary work will be undertaken by artificial intelligence initially, it is better to understand that education is not limited to school for individuals who want to continue to play a role in economic life, and the importance of continuing to learn in different fields for individuals who continue to study. Exactly at this point, the education sector appears as an area that needs to be studied in detail under Industry 4.0. Within the scope of Industry 4.0, which is also very important besides the knowledge, an education policy which gives importance to creative thought and which is based on lifelong learning should be designed. In this study, it is aimed to discuss the effects and consequences of Industry 4.0 in the education sector. Fictional analysis and case study were used as the method of study.
\end{abstract}

Key Words: Industry 4.0, The Fourth Industrial Revolution, Education, Lifelong Learning. 


\section{INTRODUCTION}

A rapid integration process has been experienced in the world for the last fourty years. This situation, which is called globalization, brings along economic, political and social changes. With the development of information technologies and the Internet, many borders between states disappear. This makes it compulsory for countries to cooperate with other countries with common interests.

Industry 4.0, which Germany has put forward, is based on the application of modern systems based on computer technology to traditional industrial infrastructure. Thus, it is aimed to change the existing industrial processes from top to bottom. In technology-intensive new generation factories, businesses can develop the technology they need with internal R\&D studies as well as transfer them from outside the organization (EKOIQ, 2014: 1-2). However, there are some studies that need to be completed during the transition to modern factories based on new generation technology. Interpretation of the legal legislation, establishment of an infrastructure suitable for the use of modern technology, and provision of the job division by defining the duties are among the most important of these studies. Therefore, preparations for Industry 4.0 on an individual, company, industry, university and country basis should be completed without delay.

In today's markets, it is increasingly difficult for companies to protect existing customers. Manufacturers try to respond to increasing expectations and demands as quickly as possible. Increasing the production flexibility, making customized production and shortening the product release time are the most preferred ways for the companies to hold the consumers. The key to having a say in market conditions, where competition increases more and more every day, is to increase productivity in production. Thanks to Industry 4.0, it will be very easy to realize them.

Industry 4.0, which was first discussed at the Hannover Fair held in Germany, became an interesting topic on a global scale. The reason for the emergence of Industry 4.0 is that the competitive advantage with the advantage of cheap labor has passed from one of the most powerful countries of the last fifty years to the developing countries such as Brazil, China and India, such as the USA, Japan and Germany. The Industry 4.0 Working Group created in Germany has prepared an Industry 4.0 Strategy Document and determined the steps to be taken within Germany (EKOIQ, 2014: 2-3). Industry 4.0 offers new opportunities not only for developed countries but also for emerging economies. Therefore, countries that want to catch Industry 4.0 and are in the developing economy category should create road maps as soon as possible. Combining the existing industrial infrastructures, technological development levels and human capital with information technologies should be a primary goal for countries that want to maintain their competitive edge in this road map, in the environment that the new industrial revolution will bring.

\section{METHOD}

In this study, Industry 4.0 and Turkish education system, also known as the Fourth Industrial Revolution, were examined in detail, and forecasts and recommendations for the change and transformation of the education sector within the scope of Industry 4.0 were included. In this study, it is aimed to discuss the effects and consequences of Industry 4.0 in the education sector. Descriptive analysis based on secondary and tertiary data and constructing methods based on quaternary data were used together. 


\section{FINDINGS}

The "Industrial Revolution" is the gradual transformation of small workshops into industrial workshops, which extend from the late 18th to the mid-19th century, gradually producing larger scale production. It is the technological change that drives the revolution and enables the discovery of machines that can produce faster and more efficiently than small craftsmen working in small workshops (Frederick, 2016: 9). Parallel to the development of technology, the stages of industrial revolutions that have continued with the development of industry from past to present can be summarized as follows.

The First Industrial Revolution was experienced by the replacement of human power, called labor in economics, by mechanical weaving looms powered by steam power. In the 1.0 period of industry, the use of metal increased due to mechanization in production, and there were also developments in the field of transportation. The Second Industrial Revolution covers the period in which the mass production was made on the assembly line where electricity was used and the division of labor developed, beginning in the early 20th century (Kagermann, Helbig and Wahlster, 2013: 14). Railways were built during this period. Current developments have made the use of steel mandatory and steel production has increased. Due to the increase in industrial activities, the demand for energy resources has also increased and electricity and oil-based energy resources have started to be preferred instead of steam power. In this period, also referred to as Industry 2.0, the increase in production and transportation and the change of energy sources have created an environment for the emergence of the concept of electrical communication. The Third Industrial Revolution has evolved with innovations in information technologies and electronics. Telecommunication technologies became stronger and more modern in Industry 3.0 era. Industry 3.0, which gains importance especially by using the internet, can be evaluated in a different position compared to other industrial revolutions during the transition to the Fourth Industrial Revolution, which we now call Industry 4.0. During the Third Industrial Revolution, modern machines based on digital technology began to replace machines based on electricity and mechanics. The rapid development of digital technology, internet and computer has enabled the use of Industry 3.0 and micro-electronic methods to become widespread. In this period, developments based on micro-electronics technology such as atomic energy, computer, fiber-optic and chip have been experienced and experienced (Kagermann, Wahlster and Helbig, 2013: 13-14).

Nowadays, it is the Industry 4.0, also called the Fourth Industrial Revolution, which was first discussed at the Hannover Fair in 2011, which was prepared by the Working Group formed by the German Government in 2012 and presented in 2013. There is a transition phase. According to the report, in order for Industry 4.0 to be successful, eight stages must be completed. These stages are:

(1) Determination of reference hardware architecture and standardization,

(2) To be able to manage complex systems,

(3) Providing a comprehensive and high-speed communication infrastructure to the industry,

(4) Safety and security,

(5) Work organization and design,

(6) Continuity of education and professional development,

(7) Adaptation of existing legislation,

(8) Efficient use of resources (Kagermann, Wahlster and Helbig, 2013: 49-50)

With Industry 4.0, it is aimed to enable a more flexible, faster and more efficient production with less cost through smart factories using modern and communicative 
technologies. Real-time information sharing will be provided through Industry 4.0, also called the Internet of Things, and design, production and distribution systems will enable mass customization. This is a process that concerns and encompasses not only the factories but the entire society. In this context, the development process in the education sector based on the Turkish education system of Industry 4.0 is examined in detail in the section below.

Globalization, mentioned at the beginning of the study, is one of the most used concepts in the last 30-40 years regarding political and economic developments. In the education sector, globalization can be explained in several different ways. Firstly, it may be to raise individuals who can work, travel and continue their lives comfortably between countries that are in constant and close relations. The basic vision of education should be to train people who can adapt and succeed in life styles between communities from different geographies and different cultures. Because, with globalization, an individual who starts in a country will be able to continue his education in different countries or countries. Therefore, in terms of preparing for the future, the method and content of the education received today is important. With Industry 4.0, communication is expected to gain a digital dimension and the borders of communication in the world will be almost completely removed. From this point of view, it will be very important for individuals to be able to communicate and communicate with different cultures. In this part of the study, firstly, the current structure of the Turkish education system has been analyzed. Then, forecasts about the areas where Industry 4.0 will be effective in the education sector are included.

\section{Analysis of Current Education System in Turkey}

The Turkish Education System is based on the "National Education Basic Law" dated 14.06.1973 and numbered 1739 (RG, 1973-14574). Within the framework of the said law, it is aimed to raise young people for certain purposes on a national and international scale. It is aimed that young people have an international consciousness that is shaped by cultural and spiritual values and supports national and free and scientific thought. However, this approach, which has a very wide place in industrial societies, has been standing with difficulty in the face of globalization and has been re-evaluated on a global scale in recent years.

Globalization in the field of education can be defined as the creation of a system that enables the promotion and sharing of cultures specific to different identities. The most important issue in this regard is to provide a national language and culture education, which every society can proudly bear its own identity. A community of individuals who can use their mother tongue properly and own cultural values will gain awareness and respect for different languages and cultures. Therefore, a multicultural and multilingual education program has gained an important role.

Made at regular intervals between the OECD PISA (Program for International Student assesment-Program for International Student Assessment) when the test 2015 results were evaluated, Turkey reading proficiency, respectively, in math and science tests 50 , located 50 and \# 54 (OECD, 2016). Turkey for many years when we look at the global economic system in place economy among the first twenty-spangled test results, it is understood that Turkey is important in the current education policy issues. Second, a country and a technical level between the Third Industrial Revolution infrastructure in Turkey, industrial society has been implementing a system for the needs of education. In order to establish the qualified workforce and technical infrastructure required by Industry 4.0, the information society education model should be adopted. The main feature of the information society is knowledge and especially scientific knowledge. According to Özkan, "People of this age are also using information as an effective element of their life should have the knowledge and skills "(Özkan, 2009: 114). 
Training concept in Turkey, is often understood only in the education of school age. This understanding has taken place in the society as the dominant view for many years. However, it is known that in the 20th century, which is a period where rapid developments occur in many different areas, human development has developed throughout life. While this reveals that learning should not be limited to a certain age period, the concept of lifelong learning has been brought to the agenda. However, nowadays, when the change is very fast, it is unlikely that people will continue the same profession throughout their lives. The rapid development of technology provides distance education opportunities, which paves the way for individuals to specialize in different fields. It can be said that the situation will improve similarly in the near future. The fact that education is possible without time and space constraints may refute the general opinion that knowledge is a concept that can only be given by educational institutions and teachers. This raises questions about what function educational institutions will serve in the future. In developing countries such as Turkey, one of the most important steps to be taken towards the realization of development goals, is the adoption of the education system to provide lifelong learning. The concept of lifelong education should not be considered as an alternative to education in schools, but rather as a reinforcement in areas where the student is missing or feels inadequate after the education at school.

Starting in the 1970s, especially in the 1990s, information and communication technologies have progressed very rapidly. Rapid advances in technology have now led to the fact that situations that people have found impossible are now considered ordinary. The opportunities offered by information technologies to people have greatly facilitated access to information. Facilitating access to information allowed many different opinions on the same subject at the same time. This situation also caused the system in educational institutions to be shaken. The availability of information through different channels has led to the emergence of ideas that the information may differ from what the teacher tells or what is written in the book. The only source of information is not only a teacher or a book today. Turkey, far from the first days of its establishment, based on rote-saving information, often criticizing knowledge "invented" Ejecting has adopted an approach far as to review the terms and critical approach. Info producing, questioning, thinking and an educational system that supports creative ideas, unfortunately, has not yet been fully implemented in Turkey.

Another issue in the Turkish education system is that there is a quality difference in education in terms of regions and gender. The inconvenience of physical conditions in schools, lack of teachers, families in some regions still do not attach the necessary importance to the education of girls, are among the important reasons that cause this quality difference. However, the solution of this issue is not as difficult as expected. The rapid development of technology and the demise of the knowledge that information can only be obtained in school and accompanied by teachers is a critical step in this way. Using technology, it will be possible to provide quality education in different regions of the country. The important point here is not to completely abandon face-to-face education, but to increase the quality of education with the help of technology.

In Turkey, it is accepted as unchangeable knowledge, the teacher's knowledge that the transfer of people and education policies are still based on the presence of certain programs. The prevalence of widespread belief that scientific knowledge is capable of explaining all kinds of events restrains what students can do on scientific knowledge. In the program and teachercentered approach, the student has little responsibility. The teacher, the family and the state emerge as the most responsible actors. However, in order for the individual to become an adult, he / she should be able to assume his own responsibility. The first step to be taken at this point is to assume responsibilities appropriate for their age to children and young people. The task of parents, teachers and institutions is to provide environments and provide guidance for 
individuals to be aware of their responsibilities. At this point, distance education opportunities draw attention. Distance education, various cultural and vocational programs, and distance master's programs such as the most well-known e-MBA allow individuals to receive diplomas from any country in the world, not limited to the country of residence.

\section{Factors That May Affect the Education Sector in Industry 4.0 Process}

Education is one of the institutions that encourages the developments that have led to the birth of modern societies. Within the framework of the results of the industrial revolutions, the concept of education is changing and it helps to establish institutionalism which is a part of the transformation in the industry (Özdemir, 2011). The fact that information is central in new industrial societies brings educational institutions to a very important position in the field of industry development and development. While a new social network and production technology based on knowledge is developing, educational institutions should also be separated from the classical industrial society infrastructure in order to ensure transformation. A process of change for the new needs of the society should be initiated in educational institutions. According to Balay, the education policies that should be designed for the initiation of this transformation process should have the following characteristics:

I. I.Education policies should develop educational programs suitable for the change of information technologies,

II. Taking into account the speed in technological developments, education processes should not be limited to a specific education period and adults should be ensured to be subject to a continuous education process,

III. Instead of giving basic information based on memorization and without perceiving transformation, it should be based on understanding and researching subjects and events in depth,

IV. As the information provided in educational institutions explains that there is not enough level to solve all the problems encountered, it should try to increase the number of individuals learning to learn.

V. Necessary educational environment should be prepared for individuals to evaluate, think freely, discuss and investigate the problems they face,

VI. Instead of developing only verbal and numerical intelligence in education, multidimensional mind development, which includes visual, kinesthetic, rhythmic and self development, should be targeted (Balay, 2004: 67).

Education policies should be revised within the framework of the criteria required by Industry 4.0. The information society education model should be adopted and the industrial society education model should be left behind. At this point, besides managers, teachers and students, success criteria, learning styles, education programs and learning / teaching methods should change. While developing education policies compatible with Industry 4.0, approaches to standard and mass education applied in industrial societies are increasingly questioned (Toffler, 2008). Within the framework of an understanding of education that develops over time and becomes institutionalized, it is important to establish educational policies that prioritize the needs and demands of the student, taking into account his / her abilities. 


\section{DISCUSSION, CONCLUSION AND SUGGESTIONS}

Turkey is currently the 2nd and 3rd is working with a level of technical infrastructure in the Industrial Revolution. Fourth Industrial Revolution when considering Turkey's shortcomings in existing infrastructure and qualified labor issues in the industry to capture, identification and resolving urgent problems in the education policy is critical.

Education, which is one of the main tools leading the development of industrial revolutions, continued its transformation and transformation in parallel with the industrial revolutions. The main reason for the change is to train people who will reveal the information needed by new production methods. Educational institutions that have completed their transformation to meet these needs have facilitated information sharing and paved the way for globalization.

Depending on the development of the industry, the concept of information society emerges. The information society helps to adopt new approaches in educational policies. Those who will work under Industry 4.0 conditions should be able to master information and communication technologies, manage smart machines, interpret data that are products of production technologies, and produce original things in areas such as sales-marketingautomation.

In the near future, it can be said that the number of blue-collar employees will decrease and a new white-collar class with creative leadership and leadership qualities will emerge. The level of command in information and communication technologies will be decisive for who will direct the information society. In Industry 4.0, software experts who will design the systems, interfaces and sensors will come to the fore. Education models designed to raise individuals with a quality compatible with Industry 4.0 should ensure the precondition of being dynamic (Atalay et al., 2015).

The fact that blue collar workers will leave the business life with Industry 4.0 will cause a change in social relations. In this context, the new educational model should be taken into consideration as well as improving the technical infrastructure of the workforce. In the new period, education policies will take its place as a cultural tool for the spread of the infrastructure of Industry 4.0. The ERASMUS exchange programs between the Farabi at home and Exchange and the European Union countries abroad facilitate the establishment of the education infrastructure on a global basis.

The close relationship of Industry 4.0 with information-communication technologies and technical infrastructure systems increases the importance of technical and vocational education. Considering the development rate of technology, the concept of learning is not limited to a certain period, the concept of lifelong learning is adopted. In this context, individuals should be encouraged to participate in training programs and develop programs in line with their interests and needs.

In order to train the workforce that will adapt to Industry 4.0, studies should be carried out to rearrange the content of undergraduate and graduate programs, and to strengthen entrepreneurship, innovation and information and communication technologies (EBSO, 2015). In addition, universities and all other educational institutions should be actively involved in R\&D activities by specifying a specialization area. Therefore, the main goal in education policies should be distance education, which teaches learning and promotes lifelong learning and enables education without time-space constraints.

All these proposals, the information society to provide education model changes and transformations that are required to put into practice in Turkey will not be sufficient alone. Turkey's adaptation to the fourth wave of industrial production model is expected to be 
dominant in the coming years, employment will contribute positively to growth and development. With Industry 4.0, it is expected that there will be an extra $2-3 \%$ growth in economic growth on an annual basis, resulting in a 5\% net increase in employment again on an annual basis (BCG and TÜSİAD, 2016). Employment growth is a reflection of that will be needed to train the skilled workforce, the existing education system in Turkey Industry 4.0, must be restructured in a suitable frame.

Looking at the development of the industry, it is seen that the time between revolutions is getting shorter. The rapid development of technology shows that the objects, devices and systems we use today will change shape in the near future or will be replaced by another object based on a completely new technology. The development of technology is changing not only objects, but also social relations and values. People strive not to lose their jobs, to keep up with innovations and to get involved in the process. At this point, important responsibilities are always imposed on the education sector. Raising individuals who are researching, questioning, producing and embracing democratic values is among the basic goals of the education sector. These targets are also among the indispensable features for individuals who will create international awareness. Today, the values offered by education are accepted on a universal scale. One of the most important reasons for this situation is that education increases the economic, cultural and social impact area. As a result, it is seen that the limits of technology, information, trade and communication have been lifted. In fact, developments are now effective not only within the borders of the country where they occur, but also on a global scale. The acceleration of change and the dissemination of information without any restrictions or evaluations cause a number of positive and negative results. With the increasing speed in the 21 st century, it is possible to minimize the negative effects of the change on life, even to turn it into an opportunity, thanks to updates in accordance with the needs in educational policies. changes in Turkey's industry and to respond to the changing needs of a modern parallel conversion pass into the education system would be useful. 


\section{REFERENCES}

ATALAY, Y., Çeliktaş, M.S., Özgel, S. and Sonlu, G. (2015). Endüstriyel Devrimin Son Sürümünde Mühendisliğin Yol Haritası. TMMOB Makine Mühendisleri Odası Mühendis ve Makine Dergisi. (TMMOB Chamber of Mechanical Engineers Journal of Engineers and Machinery). 56(662). pp. 24-24.

BALAY, R. (2004). Küreselleşme, Bilgi Toplumu ve Eğitim. Ankara Üniversitesi Eğitim Bilimleri Fakültesi Dergisi. (Ankara University Journal of the Faculty of Educational Sciences) 37(2). pp. 61-82.

BCG and TÜSİAD, (2016). Türkiye'nin Küresel Rekabetçiliği İçin Bir Gereklilik Olarak Sanayi 4.0: Gelişmekte Olan Ekonomi Perspektifi. İstanbul: TÜSİAD.

Ege Bölgesi Sanayi Odas1, (2015). Sanayi 4.0: Uyum Sağlamayan Kaybedecek! İzmir: Ege Bölgesi Sanayi Odasi.

EKOIQ, (2014). “Akıllı Yeni Dünya Dördüncü Sanayi Devrimi Endüstri 4.0: Bilişimin Endüstriyle Buluştuğu Yer Türkiye “Akıllı” Üretime Hazır mı? EKOIQ Dergisi Özel Eki. (EKOIQ Journal Special Issue) D. December, pp. 1-17.

FREDERICK, D. E., (2016). Libraries, Data and the Fourth Industrial Revolution (Data Deluge Column). Library Hi Tech News. 33(5). ss. 9-12.

KAGERMANN, H.; HELBIG, J. ve WAHLSTER, W. (2013). "Recommendations for Implementing the Strategic Initiative Industrie 4.0", Final report fort he Industrie 4.0 Working Group, Ed: Ariane Hellinger ve Veronika Stumpf, acatech-National Academy of Science and Engineering. April. Ss. 13-78.

OECD, (2016). International Student Evaluation Program PISA 2015 National Report. http://pisa.meb.gov.tr/wp-content/uploads/2014/11/PISA2015_UlusalRapor.pdf Date of Access: 18.12.2018

ÖZDEMİR, S.M. (2011). Toplumsal Değişme ve Küreselleşme Bağlamında Eğitim ve Eğitim Programları: Kavramsal Bir Çözümleme. Ahi Evran Üniversitesi İletişim Fakültesi Dergisi. (Ahi Evran University Journal of the Faculty of Communication).12(1). pp. 85110 .

ÖZKAN, H., (2009). Bilgi Toplumu Eğitim Programları. Süleyman Demirel Üniversitesi Sosyal Bilimler Enstitüsü Dergisi. (Suleyman Demirel University Journal of the Institute of Social Sciences). 2(10). pp. 113-132.

Resmi Gazete, (1973). Milli Eğitim Temel Kanunu. 1739/14574.

TOFFLER, A. (2008). Üçüncü Dalga (translator: Selim Yeniçeri). 1. Baskı. İstanbul: Koridor Publishing. 
AKGÜL \& AYER / Examining the Impact of Industry 4.0 on Education 